\title{
1 Assessment of global mercury deposition through litterfall
}

2 Xun Wang ${ }^{1,2}$, Zhengduo Bao ${ }^{3,4}$, Che-Jen $\operatorname{Lin}^{1,3,4, *}$, Wei Yuan ${ }^{1,2}$, Xinbin Feng ${ }^{1, *}$

3

5

6

7

8

9

10

11

12

13

14

\section{Contents}

16 S1 Litterfall sample collection and measurement for unpublished $\mathrm{Hg}$ dataset

17

18

19

20

21

22

23

24

25
${ }^{1}$ State Key Laboratory of Environmental Geochemistry, Institute of Geochemistry, Chinese Academy of Sciences, Guiyang, China

${ }^{2}$ University of Chinese Academy of Sciences, Beijing, China

${ }^{3}$ Center for Advances in Water and Air Quality, Lamar University, Beaumont, TX, USA

${ }^{4}$ Department of Civil and Environmental Engineering, Lamar University, Beaumont, TX, USA

* Corresponding Authors:

Xinbin Feng

Phone: +86-851-5895728

Che-Jen Lin

Phone: (409) 880-8761

Fax: (409) 880-8121

E-mail: Jerry.Lin@lamar.edu

S2 The Monte Carlo Simulation ..............53

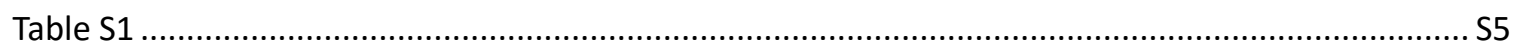

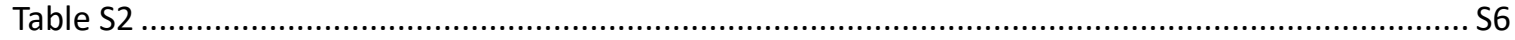

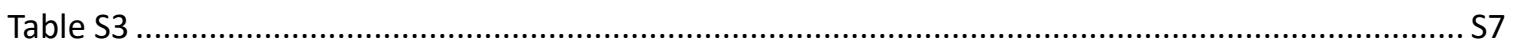

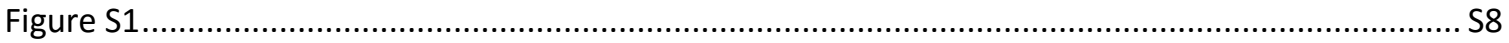

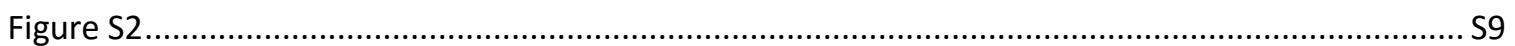

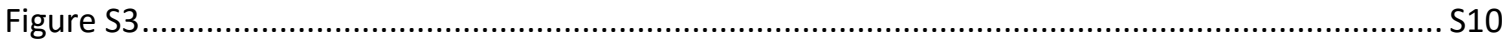


This dataset includes $\mathrm{Hg}$ concentration in litterfall collected under 5 predominant tree 28 species in 4 national subtropical evergreen forests (Xishuangbanna: 21.68 N, $101.42 \mathrm{E}$; 29 Jianfengling: 19.18 N, 109.73 E; Shenlongjia: 31.45 N, 109.91 E; Mt. Wuyi: 28. 04 N, $30 \quad 117.57 \mathrm{E}$ ) and 4 national temperate forests (Jixian: $36.16 \mathrm{~N}, 110.73 \mathrm{E}$; Mt. Xiaolong: 34.35 31 N, 106.01 E; Mt. Xiaoxinganling: 47.17 N, 128.95 E; Mt. Taihang: 34.96 N, 112.4 E).

32 Dominant plant species in these sites include Gironniera subaequalis Planch, Pometia 33 pinnata, Barringtonia racemose, Alseodaphne hainanensis Merr, etc.

34 The collection of litter samples, measurement of $\mathrm{Hg}$ concentration and the quality 35 control procedure have been described elsewhere 1. Briefly, litterfall samples were 36 collected by $1 \mathrm{~m} \times 1 \mathrm{~m} 1 \mathrm{~m} \times 1 \mathrm{~m}$ nylon nets hanging $1 \mathrm{~m}$ above ground at eight random 37 locations under EB forest. Litterfall samples were placed into paper bags, air-dried in a 38 clean room at the ASSFERS, ground in an agate mortar and sieved by a 200 mesh sieve $39(74 \mu \mathrm{m}){ }^{1}$. The total $\mathrm{Hg}$ concentrations were measured by a Lumex RA-915+ 40 multifunctional $\mathrm{Hg}$ analyzer equipped with a pyrolysis attachment. Duplicated 41 measurements for $\mathrm{Hg}$ were performed and accepted variations of replicated measurements 42 were below 5\%. Standard samples were measured in every 10 samples with recoveries in 43 the range of 95\%-105\% GBW10020 (GSB-11) as litter Hg standard. 
The simulation was carried out in three steps: creating statistical distribution using the 47 observational data, perform random sampling, and flux calculation. In the first step, $\mathrm{Hg}$ concentration in litters and litterfall biomass production were regarded as random variables:

$$
H g_{i}(\theta)=f_{\theta}\left(x_{1}, x_{2}, \ldots, x_{n} \mid \theta\right)
$$

$$
\operatorname{Biomass}_{i}(\beta)=f_{\beta}\left(x_{1}, x_{2}, \ldots, x_{n} \mid \beta\right)
$$

51 where $\theta$ is a random variable vector for $\mathrm{Hg}$ concentrations in a given type of biomes 52 group (total number of group is 14); $\beta$ is the random variable vector for litterfall biomass 53 production in $i$ group $\left(\mathrm{g} \mathrm{m}^{-2} \mathrm{yr}^{-1}\right)$. Function $f$ represents the associated probability density 54 function. As such, $F_{\theta}$ and $F_{\beta}$ represent the respective cumulative probability distribution 55 functions.

56 After determining the respective probability density functions of the data, an inverse 57 transformation method was utilized to generate a random sample from the probability 58 density distribution ${ }^{2}$. For example, the random sample for $\mathrm{Hg}$ concentration (X) was 59 generated using:

$$
\text { Returning: } X=F_{\theta}^{-1}(U)
$$

where $\mathrm{U}$ is a uniform distribution and $F_{\theta}{ }^{-1}$ denotes the inverse of $F_{\theta}$. Similarly, the random sample for litterfall biomass production can be described as:

$$
X_{\beta, i} \sim F_{\beta}(U)^{-1}
$$

Therefore, the random variable of $\mathrm{Hg}$ deposition flux caused by litterfall $\left(L_{i}\right)$ can be expressed as:

$$
L_{i}=X_{\theta, i} X_{\beta, i}
$$

After 50,000 sampling iterations, the descriptive statistics and the $95 \%$ confidence interval (CI) of $L_{i}$ were calculated from the probability distribution of $L_{i}$. The Monte Carlo 
simulation and $\mathrm{Hg}$ flux calculation was performed using MATLAB 2013a and ArcGIS 10.3.

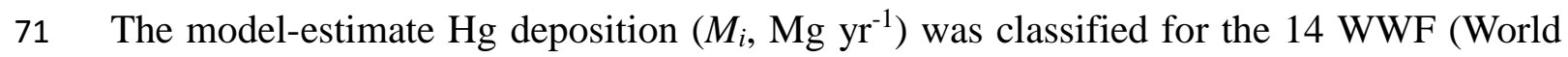

72 Wildlife Fund for Nature) biomes:

$73 \quad M_{i}=\frac{L_{i}}{t_{d, i}} \times t_{n, i} \times \sigma$

Where $L_{i}$ is $\mathrm{Hg}$ deposition flux caused by litterfall; $\sigma$ is the ratio for unit conversion; $t_{d, \mathrm{i}}$ is tree density (stems ha $\left.{ }^{-1}\right) ; t_{n, i}$ is total number of trees in the $i$ th biomes type compiled 76 from a best estimate in a recent study ${ }^{3}$ (http://elischolar.library.yale.edu/yale_fes_data/1).

77 The global spatial distribution of $\mathrm{Hg}$ deposition through litterfall was then calculated 78 based on the spatial distribution of tree density.

79 For the biome types that few data exist (e.g., desert and xeric shrub lands, mangroves, 80 and flooded grasslands), a surrogate for $\mathrm{Hg}$ input per tree $\left(\frac{L_{i}}{t_{d, i}}\right)$ in Eq. 7 is applied to 81 represent global spatial distribution. Evergreen broadleaf species dominate in tropical and 82 subtropical broadleaf moist forests and mangroves, which have comparable litterfall 83 biomass production ${ }^{4}$. The value of $\frac{L_{i}}{t_{d, i}}$ observed in tropical and subtropical broadleaf 84 moist forests is therefore applied for mangroves. Limited data in the ORNLDAAC database 85 shows litterfall biomass production in desert and xeric shrub lands is $137-916 \mathrm{Mg} \mathrm{km}^{-1}$ $86\left(552 \pm 350 \mathrm{Mg} \mathrm{km}^{-2}, \mathrm{n}=5\right)$. Such values are close to the observations for tundra (430-1185 $87 \mathrm{Mg} \mathrm{km}^{-2}, \mathrm{n}=12$ ). Hence, the litterfall biomass productions for the two biomes was 88 combined together during the Monte Carlo simulation with the same $\frac{L_{i}}{t_{d, i}}$. The mean $89 \frac{L_{i}}{t_{d, i}}$ value from temperate grasslands and shrublands is applied for flooded grasslands and 90 savanna and montane grasslands. 
93 Table S1 The dataset of unpublished $\mathrm{Hg}$ concentration collected in China in autumn of

$94 \quad 2013$ and 2014.

95

\begin{tabular}{ccccccc}
\hline Code & Country & Tree species/forest type & Type & Lat $\left(^{\circ}\right)$ & lon $\left(^{\circ}\right)$ & Hg concentration $\left(\mathrm{ng} \mathrm{g}^{-1}\right)$ \\
\hline 1 & China & evergreen forests & Remote & 31.45 & 109.91 & 92 \\
2 & China & evergreen forests & Remote & 28.04 & 117.57 & 45 \\
3 & China & evergreen forests & Remote & 19.18 & 109.73 & 78 \\
4 & China & evergreen forests & Remote & 22.00 & 100.80 & 74 \\
5 & China & evergreen forests & Remote & 36.16 & 110.73 & 58 \\
6 & China & Deciduous forests & Remote & 39.97 & 126.41 & 40 \\
7 & China & Deciduous forests & Remote & 34.96 & 112.40 & 62 \\
8 & China & Deciduous forests & Remote & 29.84 & 106.40 & 40 \\
9 & China & Deciduous forests & Remote & 36.16 & 110.73 & 47 \\
\hline
\end{tabular}

96 
97 Table S2 Simulated distributions for $\mathrm{Hg}$ concentrations in litterfall $\left(\mathrm{ng} \mathrm{g}^{-1}\right)$ and for litterfall 98 biomass productions $\left(\mathrm{Mg} \mathrm{km}^{-2}\right)$ in documented literatures. The parameter for each 99 distribution was described in details at http://www.mathworks.com/help/stats/fitdist.html. 100 The detailed information of each biomass was showed in Figure 5. Hg_EB means the 101 dataset for $\mathrm{Hg}$ concentration in litterall from the evergreen broadleaf forests, and Hg_Other 102 means from the other forest types.

103

\begin{tabular}{llll}
\hline Type & Mean \pm SD & Distribution & Site_num \\
\hline Hg_EB & $63 \pm 28$ & Weibull: $A=26, B=0.5$ & 37 \\
Hg_Other & $45 \pm 12$ & Normal: $\mu=45, \sigma=12$ & 119 \\
\hline C1 & $773 \pm 319$ & Weibull: $\mathrm{A}=930, \mathrm{~B}=2$ & 134 \\
C2 & $412 \pm 278$ & Rayleigh: $\mathrm{B}=293$ & 28 \\
C3 & $371 \pm 217$ & Weibull: $\mathrm{A}=418, \mathrm{~B}=2$ & 72 \\
C4 & $407 \pm 564$ & t Location-Scale: $\mu=407, \sigma=142, \mathrm{~F}=4$ & 339 \\
C5 & $364 \pm 180$ & Weibull: $\mathrm{A}=411, \mathrm{~B}=2$ & 69 \\
C6 & $196 \pm 96$ & Rician: $\mathrm{s}=136, \sigma=120$ & 45 \\
C7 & $322 \pm 151$ & Weibull: $\mathrm{A}=390, \mathrm{~B}=2$ & 16 \\
C8 & $290 \pm 137$ & Lognormal: $\log (\mu)=5.6, \log (\sigma)=0.4$ & 42 \\
C10 & $300 \pm 259$ & Rician: $\mathrm{s}=205, \sigma=230$ & 26 \\
C11_C13 & $115 \pm 65$ & Rician: $\mathrm{s}=96, \sigma=52$ & 17 \\
C12 & $564 \pm 316$ & Weibull: $\mathrm{A}=635, \mathrm{~B}=2$ & 26 \\
\hline
\end{tabular}


105 Table S3 Total trees (TT, billions), tree density (TD, stems ha $\left.{ }^{-1}\right)^{3}, \mathrm{Hg}$ deposition through litterfall 106 (per tree) of global terrestial biomes (HP, $\mathrm{mg} \mathrm{yr}^{-1}$ ).

107

\begin{tabular}{lcccc}
\hline Type & Description & TT & TD & HP \\
\hline C1 & Tropical and Subtropical Moist Broadleaf Forests & $799.4 \pm 24.0$ & $780 \pm 23$ & $0.62 \pm 0.39$ \\
C2 & Tropical and Subtropical Dry Broadleaf Forests & $156.4 \pm 1.3$ & $311 \pm 2$ & $0.61 \pm 0.49$ \\
C3 & Tropical and Subtropical Coniferous Forests & $22.2 \pm 0.4$ & & $0.37 \pm 0.05$ \\
C4 & Temperate Broadleaf and Mixed Forests & $362.6 \pm 2.9$ & $485 \pm 4$ & $0.38 \pm 0.19$ \\
C5 & Temperate Conifer Forests & $150.6 \pm 2.3$ & $428 \pm 6$ & $0.37 \pm 0.21$ \\
C6 & Boreal Forests & $749.3 \pm 50.1$ & $947 \pm 63$ & $0.09 \pm 0.05$ \\
C7 & Tropical and Subtropical Grasslands,Savannas and Shrublands & $318.0 \pm 35.5$ & $263 \pm 30$ & $0.60 \pm 0.44$ \\
C8 & Temperate Grasslands,Savannas and Shrublands & $148.3 \pm 4.9$ & $290 \pm 10$ & $0.44 \pm 0.23$ \\
C9 & Flooded Grasslands,Savannas & $64.6 \pm 14.2$ & $508 \pm 110$ & $0.27 \pm 0.19$ \\
C10 & Montane Grasslands,Savannas & $60.3 \pm 24.0$ & $834 \pm 332$ & $0.17 \pm 0.09$ \\
C11 & Tundra & $94.9 \pm 6.3$ & $1064 \pm 67$ & $0.06 \pm 0.05$ \\
C12 & Mediterranean Forests, Woodlands and Scrub & $53.4 \pm 1.2$ & $872 \pm 16$ & $0.28 \pm 0.18$ \\
C13 & Deserts and Xeric Shrublands & $53.0 \pm 2.9$ & $245 \pm 14$ & $0.06 \pm 0.05$ \\
C14 & Mangroves & $8.2 \pm 0.3$ & $540 \pm 66$ & $0.62 \pm 0.46$ \\
\hline
\end{tabular}




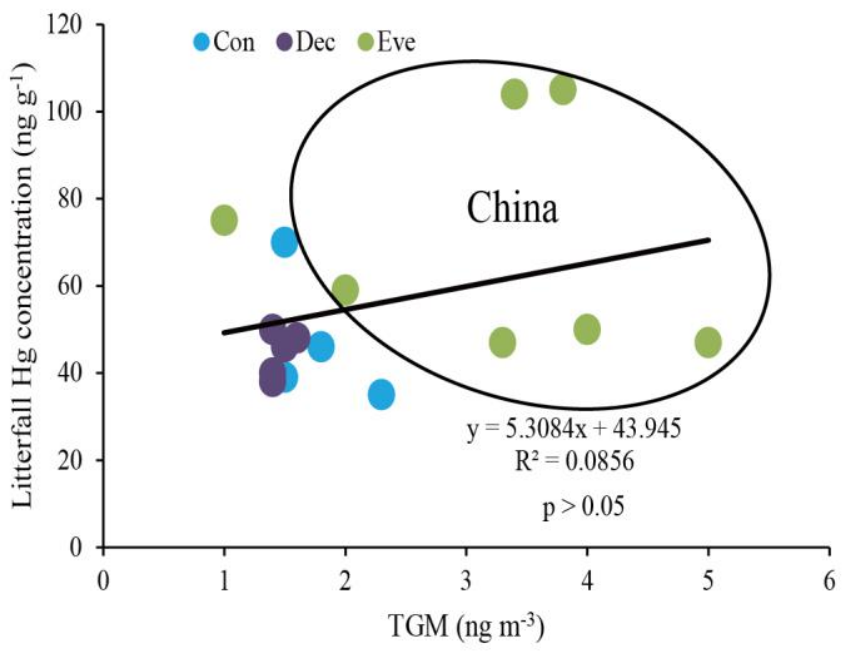

110

111

112

113

114

115
Figure S1 Correlation between $\mathrm{Hg}$ concentration in litterfall and annual mean atmospheric $\mathrm{Hg}^{0}$ concentration. Two sites in $\mathrm{CHI}$ with much elevated $\mathrm{Hg}$ concentration are from the dataset used for the modeling of the $\mathrm{Hg}$ concentration distribution because their $\mathrm{Hg}$ concentrations fall out of the range of Mean \pm 3 SD based on the Pauta Criterion. 


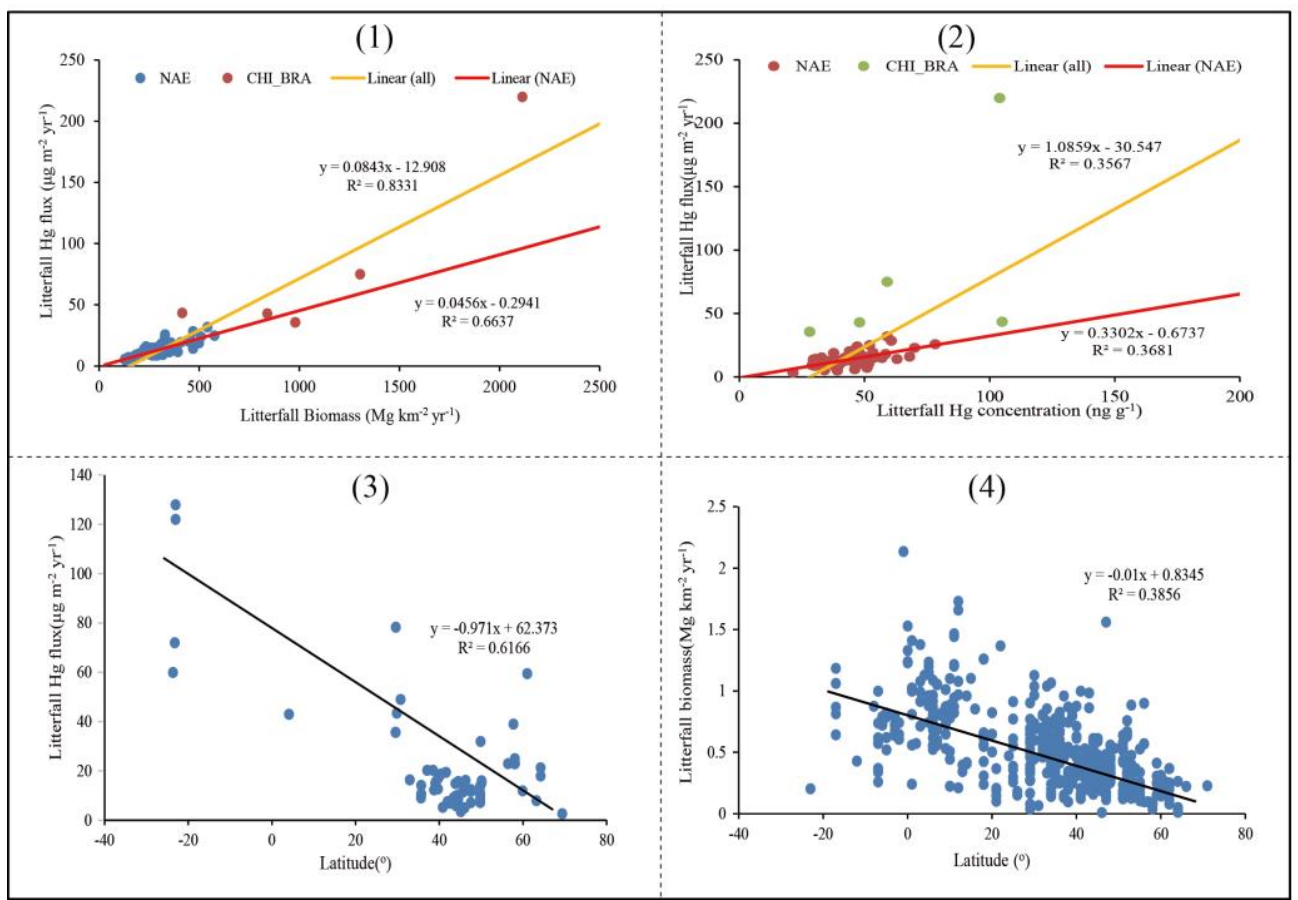

Figure S2: (1) Correlation between $\mathrm{Hg}$ deposition through litterfall and litterfall biomass 118 production. (2) Correlation between $\mathrm{Hg}$ deposition through litterfall and $\mathrm{Hg}$ concentration 119 in litterfall. (3) Correlation between $\mathrm{Hg}$ deposition through litterfall and latitude. (4) 120 Correlation between litterfall biomass production and latitude. 
122

123

124
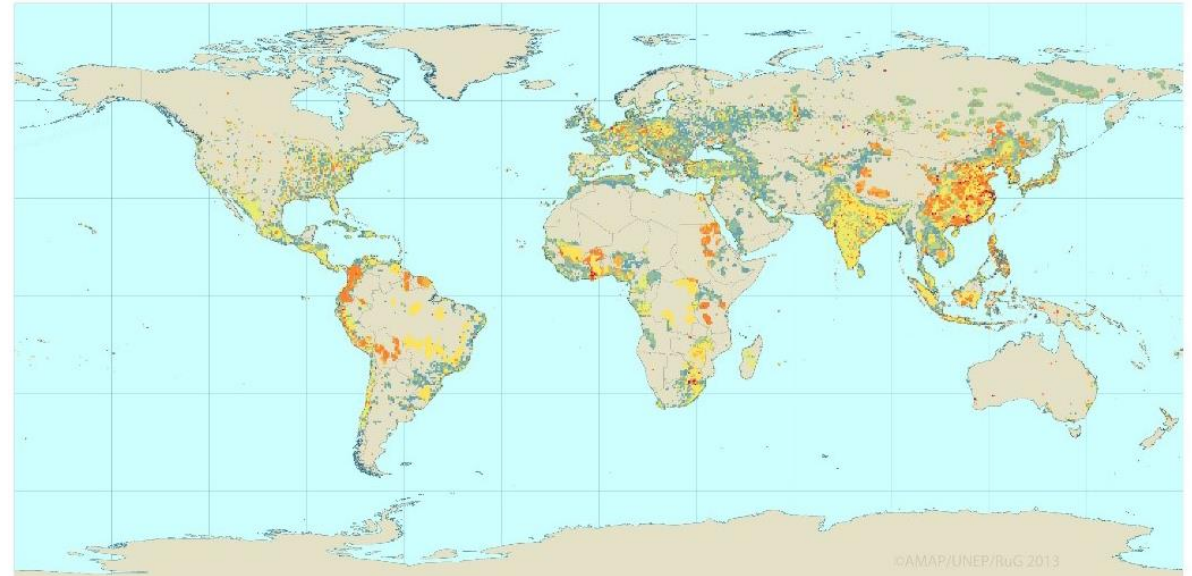

Figure S3 Geospatial distribution of global anthropogenic mercury emissions to air (2010) 5 


\section{Literature cited}

127

128 1. Zhou, J.; Feng, X. B.; Liu, H. Y.; Zhang, H.; Fu, X. W.; Bao, Z. D.; Wang, X.; Zhang, Y. P., Examination of 129 total mercury inputs by precipitation and litterfall in a remote upland forest of Southwestern China. Atmos 130 Environ 2013, 81, 364-372.

131 2. Raychaudhuri, S., INTRODUCTION TO MONTE CARLO SIMULATION. Proceedings of the 2008 Winter 132 Simulation Conference 2008, 91-100.

133 3. Crowther, T. W.; Glick, H. B.; Covey, K. R.; Bettigole, C.; Maynard, D. S.; Thomas, S. M.; Smith, J. R.; 134 Hintler, G.; Duguid, M. C.; Amatulli, G.; Tuanmu, M. N.; Jetz, W.; Salas, C.; Stam, C.; Piotto, D.; Tavani, R.; 135 Green, S.; Bruce, G.; Williams, S. J.; Wiser, S. K.; Huber, M. O.; Hengeveld, G. M.; Nabuurs, G. J.; Tikhonova, 136 E.; Borchardt, P.; Li, C. F.; Powrie, L. W.; Fischer, M.; Hemp, A.; Homeier, J.; Cho, P.; Vibrans, A. C.; Umunay, P. 137 M.; Piao, S. L.; Rowe, C. W.; Ashton, M. S.; Crane, P. R.; Bradford, M. A., Mapping tree density at a global 138 scale. Nature 2015, 525, (7568), 201-205.

139 4. Zhang, H. C.; Yuan, W. P.; Dong, W. J.; Liu, S. G., Seasonal patterns of litterfall in forest ecosystem 140 worldwide. Ecol Complex 2014, 20, 240-247.

141 5. Wilson, S.; Kindbom, K.; Steenhuisen, F.; Munthe, J.; Yaramenka, K.; Telmer, K., Technical Background 142 Report for the Global Mercury Assessment 2013. 2013; p 4-68. 